\title{
Simple, sensitive and rapid determination of linifanib (ABT-869), a novel tyrosine kinase inhibitor in rat plasma by UHPLC-MS/MS
}

\author{
Muzaffar lqbal ${ }^{1,2^{*}}$, Essam Ezzeldin², Tanveer A Wani ${ }^{1}$ and Nasr Y Khalil ${ }^{1}$
}

\begin{abstract}
Background: Linifanib (ABT-869) is an orally active receptor tyrosine kinase inhibitor, which simultaneously inhibits vascular endothelial and platelet derived growth factor receptor. The aim of the present study was to develop an UHPLC-MS/MS method for the quantification of linifanib in rat plasma to support the pharmacokinetic and toxicokinetic studies.
\end{abstract}

Results: Linifanib was separated on Acquity UPLC BEH ${ }^{\mathrm{TM}} \mathrm{C}_{18}$ column $(50 \times 2.1 \mathrm{~mm}$, i.d. $1.7 \mu \mathrm{m})$ using acetonitrile-10 mM ammonium acetate $(60: 40, v / v)$ as an isocratic mobile phase at a flow rate of $0.3 \mathrm{~mL} / \mathrm{min}$ with sunitinib as internal standard (IS). Detection was performed on tandem mass spectrometer using electrospray ionization source in positive mode by multiple reaction monitoring. The monitored transitions were set at $\mathrm{m} / \mathrm{z}$ $376.05>250.97$ for linifanib and m/z $399.12>283.02$ for IS, respectively. Both linifanib and IS were eluted at 0.68 and $0.44 \mathrm{~min}$, respectively with a total run time of $2.0 \mathrm{~min}$ only. The calibration curve was found to be linear over the concentration range of $0.40-500 \mathrm{ng} / \mathrm{mL}$. The intra- and inter-day precision value was $\leq 10.6 \%$ and the accuracy ranged from $90.9-108.9 \%$. In addition, all the validation results were within general assay acceptability criteria according to guidelines of bio-analytical method validation.

Conclusion: A selective and sensitive UHPLC-MS/MS method was developed and validated for the determination of linifanib in rat plasma for the first time. The developed method is simple, sensitive and rapid in terms of chromatographic separation and sample preparation and was successfully applied in a pilot pharmacokinetic study in rats.

Keywords: Linifanib, ABT-869, UHPLC-MS/MS, Rat plasma, Pharmacokinetics

\section{Background}

Vascular endothelial and platelet derived growth factor receptor (VEGFR and PDGFR) plays a major role in angiogenesis and tumor cell proliferation. It has been reported that the simultaneous inhibition of these two receptors achieves greater antitumor activities than inhibition of either receptor alone [1,2]. Linifanib (ABT869 ) is an orally active novel small molecule multi-target receptor tyrosine kinase (RTK) inhibitor, which simultaneously inhibits VEGFR and PDGFR with minimal activity against unrelated RTKs. It has potent inhibitory activity against VEGFR-1, VEGFR-2, PDGFRb, colony-

\footnotetext{
*Correspondence: muziqbal@gmail.com

'Department of Pharmaceutical Chemistry, College of Pharmacy, King Saud University, P.O. Box 2457, Riyadh 11451, Saudi Arabia ${ }^{2}$ Bioavailability Laboratory, College of Pharmacy, King Saud University, P.O. Box 2457, Riyadh, Saudi Arabia
}

stimulating factor 1 receptor, and fms-related tyrosine kinase 3 , with minimal activity against unrelated tyrosine and serine/threonine kinases [3-5]. Linifanib has shown prominent antitumor activity against solid tumors in phase 2 studies e.g. non-small cell lung cancer, hepatocellular carcinoma and renal cell carcinoma [6-9] and presently are in phase 3 studies in patients with hepatocellular carcinoma [9].

Based on the available preliminary phase I study data, the pharmacokinetics of linifanib was dose proportional and time invariant. It was rapidly absorbed with peak plasma concentration achieved in approx. $2 \mathrm{~h}$ across all dose levels. The oral clearance was $2.7 \mathrm{~L} / \mathrm{h}$, and the main systemic metabolite was the carboxylate metabolite and only $15 \%$ of the dose was recovered as unchanged in urine $[10,11]$. 
Considering linifanib as a new potential antitumor drug, a selective and sensitive bioanalytical method is required for its pharmacokinetic and toxicokinetic studies. The chromatographic separation procedure of reported LC-MS/MS method (for linifanib and its acid metabolite) in plasma requires pre-column back wash and takes more than $6 \mathrm{~min}$ to complete the one sample analysis [12]. Though its extraction procedure was based on automated liquid liquid extraction (high-throughput), but mean extraction recovery was only $18 \%$ and it also required Hamilton automated liquid handler with 96 well plates for operation. Wu $\mathrm{H}$ et al 2008, used salting-out assisted liquid/liquid extraction procedure, but the recovery couldn't exceeded of 40\% [13]. Amongst the available analytical techniques, UHPLC has gained a considerable attention due to use of Acquity BEH column, which not only increased the separation throughput and efficiency but also reduced the retention time and volume of solvent required during separation [14-16]. The aim of the present study was to develop a sensitive UHPLC-MS/MS method, which can facilitate the rapid determination of linifanib in plasma using simple chromatographic separation and sample preparation procedure.

\section{Experimental}

\section{Chemicals and reagents}

Linifanib (purity $\geq 98 \%$ ) was purchased from Weihua Pharma Co., Limited, Zhejiang, China and sunitinib malate (internal standard; purity $\geq 98 \%$ ) was purchased from Sigma-Aldrich, USA (Figure 1). Methanol and acetonitrile were of HPLC grade obtained from Winlab Laboratory, whereas formic acid and ammonium acetate were of analytical grade obtained from BDH Laboratory, England. All aqueous solutions used in this study were obtained from Milli-QR Gradient A10R (Millipore, Moscheim Cedex, France) having pore size $0.22 \mu \mathrm{m}$. Blank rat plasma was separated from the healthy rats which obtained from the Animal Care and Use Centre, College of Pharmacy, King Saud University, Riyadh, Saudi Arabia.

\section{Preparation of stock solutions, calibration standards and quality control samples}

Standard stock solutions of $1.0 \mathrm{mg} / \mathrm{mL}$ were prepared for linifanib in methanol and sunitinib (IS) in dimethyl sulphoxide by dissolving the accurate amounts of their reference standards. A series of working standard solutions of linifanib were prepared by further dilution of the stock solution using acetonitrile. All stock solutions and working solutions were kept in refrigerator at $4{ }^{\circ} \mathrm{C}$. Plasma calibration standards were prepared by spiking the appropriate amounts of the working standard solutions into blank plasma to obtain final concentration levels of $0.40,1.13,3.24,10.80,36.0,120,300$ and $500 \mathrm{ng} / \mathrm{mL}$. Quality control (QC) samples at four different concentrations: $0.45,1.28,42.50$ and $425 \mathrm{ng} / \mathrm{mL}$ in blank rat plasma were also prepared in a similar manner and treated as LOQ QC, LQC, MQC and HQC respectively. Both plasma calibration standards and QC samples were kept at $-80^{\circ} \mathrm{C}$ until used during validation and/or sample analysis. The IS working solution $(1 \mu \mathrm{g} / \mathrm{mL})$ for routine use was prepared by diluting the IS stock solution in acetonitrile and were stored at $4^{\circ} \mathrm{C}$.

\section{UHPLC separation and MS/MS parameters}

The equipment consisted of ACQUITY ${ }^{\mathrm{xM}}$ UHPLC system coupled to triple-quadruple tandem mass spectrometer (Waters Corp., Milford, MA, USA). The UHPLC system consisted of quaternary solvent manager, a binary pump, degasser, autosampler with an injection loop of $10 \mu \mathrm{L}$ and a column heater-cooler. The chromatographic separation was performed on Acquity $\mathrm{BEH}^{\mathrm{Ts}} \mathrm{C}_{18}$ column $(50 \times 2.1 \mathrm{~mm}$, i.d., $1.7 \mu \mathrm{m}$, Waters, USA $)$ maintained at ambient temperature. The mobile phase was comprised of acetonitrile: $10 \mathrm{mM}$ ammonium acetate $(60: 40, \mathrm{v} / \mathrm{v})$ at a flow rate of $0.3 \mathrm{~mL} / \mathrm{min}$. Linifanib and IS were eluted at 0.68 and $0.44 \mathrm{~min}$ respectively with a total run time of $2.0 \mathrm{~min}$ only. The injection volume was $5 \mu \mathrm{L}$ in partial loop mode and the temperature of the autosampler was $10^{\circ} \mathrm{C}$.

Triple-quadruple tandem mass spectrometer equipped with electrospray ionization (ESI) interface was used for analytical detection. The detection was obtained in ESI positive mode using multiple reaction monitoring (MRM), with transition channels of proton molecular ions was $\mathrm{m} / \mathrm{z} 376.05>250.97$ for linifanib and $\mathrm{m} / \mathrm{z} 399.12>283.02$ for IS, having dwell time of $0.106 \mathrm{~s}$. Nitrogen was used as a desolvating gas at a flow rate of $600 \mathrm{~L} / \mathrm{h}$. The desolvating temperature was $350^{\circ} \mathrm{C}$ whereas source temperature was $150^{\circ} \mathrm{C}$. The collision gas (argon) flow was $0.1 \mathrm{~mL} / \mathrm{min}$ and capillary voltage was set at $3.5 \mathrm{kV}$. The compound parameters like cone voltage and collision energy were set at $46 \mathrm{~V} \& 30 \mathrm{eV}$ for linifanib and $36 \mathrm{~V}$ \& $22 \mathrm{eV}$ for IS respectively. The Mass Lynx software (Version 4.1, SCN 714) was used to control the UHPLC-MS/MS system and data was collected and processed using Target Lynx $^{\mathrm{TM}}$ program.

\section{Sample preparation}

Plasma samples stored at around $-80^{\circ} \mathrm{C}$ were thawed, left for $1 \mathrm{~h}$ at room temperature and vortexed for $30 \mathrm{sec}$ before extraction. In a fresh $1.5 \mathrm{~mL}$ centrifuge tube, $200 \mu \mathrm{L}$ plasma (calibration standards, QCs and unknown samples) followed by $20 \mu \mathrm{L}$ of IS $(1 \mu \mathrm{g} / \mathrm{mL})$ was added. The sample was vortexed for $30 \mathrm{sec}$ and again by addition of $15 \mu \mathrm{L}$ of formic acid to each tube. After vortexed, $445 \mu \mathrm{L}$ of acetonitrile was added and again vortexed gently for $2 \mathrm{~min}$, then centrifuged for $8 \mathrm{~min}$ at $12500 \mathrm{rpm}$ at $4^{\circ} \mathrm{C}$. After centrifugation, supernatant 
<smiles>Cc1ccc(F)c(NC(=O)Nc2ccc(-c3cccc4[nH]nc(N)c34)cc2)c1</smiles>

Linifanib<smiles>CCN(CC)CCNC(=O)c1c(C)[nH]c(C=C2C(=O)Nc3ccc(F)cc32)c1C</smiles>

Sunitinib

Figure 1 Chemical structure of linifanib and sunitinib.

was transferred to a clean tube, and evaporated to dryness under a stream of nitrogen at approximately $40^{\circ} \mathrm{C}$. The residue was reconstituted in $200 \mu \mathrm{L}$ of the mobile phase, vortexed for $30 \mathrm{sec}$ and $5 \mu \mathrm{L}$ was injected into UPLCMS/MS for analysis.

\section{Method validation}

A full method validation was performed according to guidelines set by the United States Food and Drug Administration and European Medicines Agency [17,18]. The developed method was validated in terms of selectivity,

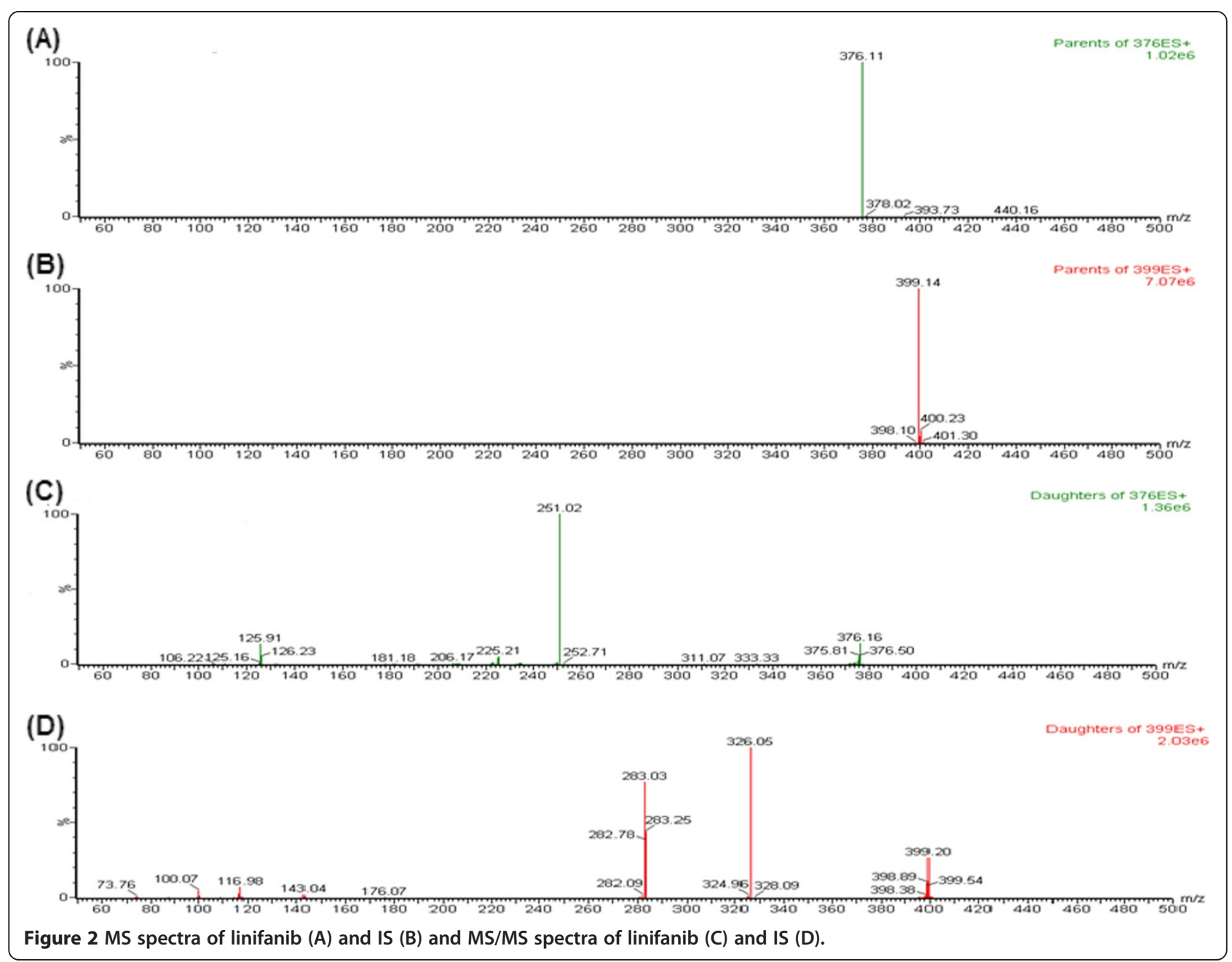


linearity of response, accuracy, precision, recovery, matrix effects, dilution integrity and stability of the analytes during both short-term sample processing and long-term storage.

Method selectivity was investigated by the comparison of chromatograms of blank plasma obtained from different healthy rats with the corresponding chromatograms of plasma samples spiked at LLOQ $(0.40 \mathrm{ng} / \mathrm{mL})$ level of the analyte and $100 \mathrm{ng} / \mathrm{ml}$ of the IS.

The linearity of the method was determined by performing the three calibration curves with eight different concentrations ranging from $0.40-500 \mathrm{ng} / \mathrm{mL}$. The correlation coefficient $r^{2}>0.995$ was desirable for all the calibration curves. The peak area ratios of the analyte to IS were calculated and the calibration curves were established by fitting these ratios to the corresponding concentrations using weighted least square linear regression. The lowest concentration of the analyte $(0.40 \mathrm{ng} / \mathrm{mL})$ on the calibration curve was considered as LLOQ with acceptable accuracy and precision.

The precision of the assay is expressed as percentage coefficient of variation (\% CV), whereas accuracy is expressed as a percentage deviation from the respective nominal value. For precision and accuracy, QC samples at four different concentration levels (LOQ QC, LQC, MQC and $\mathrm{HQC}$ ) were analyzed in six replicates on the same day (intra-day) and on three different days (inter-day) respectively. The deviation in mean value of precision should not exceed $20 \%$ for the lowest QC samples and $15 \%$ for the other QC samples and accuracy should be within $\pm 20 \%$ for the lowest QC samples and $\pm 15 \%$ for the other QC samples.

The extraction recovery of linifanib at three QC levels and IS at $100 \mathrm{ng} / \mathrm{mL}$ were evaluated by comparing peak area ratios of plasma spiked with analyte prior to extraction with the peak area ratios of plasma spiked with analyte after the extraction. Calculation of the matrix effects was conducted by calculating the peak area ratio of extracted rat plasma post spiked with analyte to the peak area of the analyte in reconstitution solution in the same concentration. Deviation in linifanib and IS concentrations of a maximum of $15 \%$ were considered acceptable as recommended in EMEA bioanalytical guideline [18].

The stability of linifanib in rat plasma during the sample storage and processing conditions was assessed by

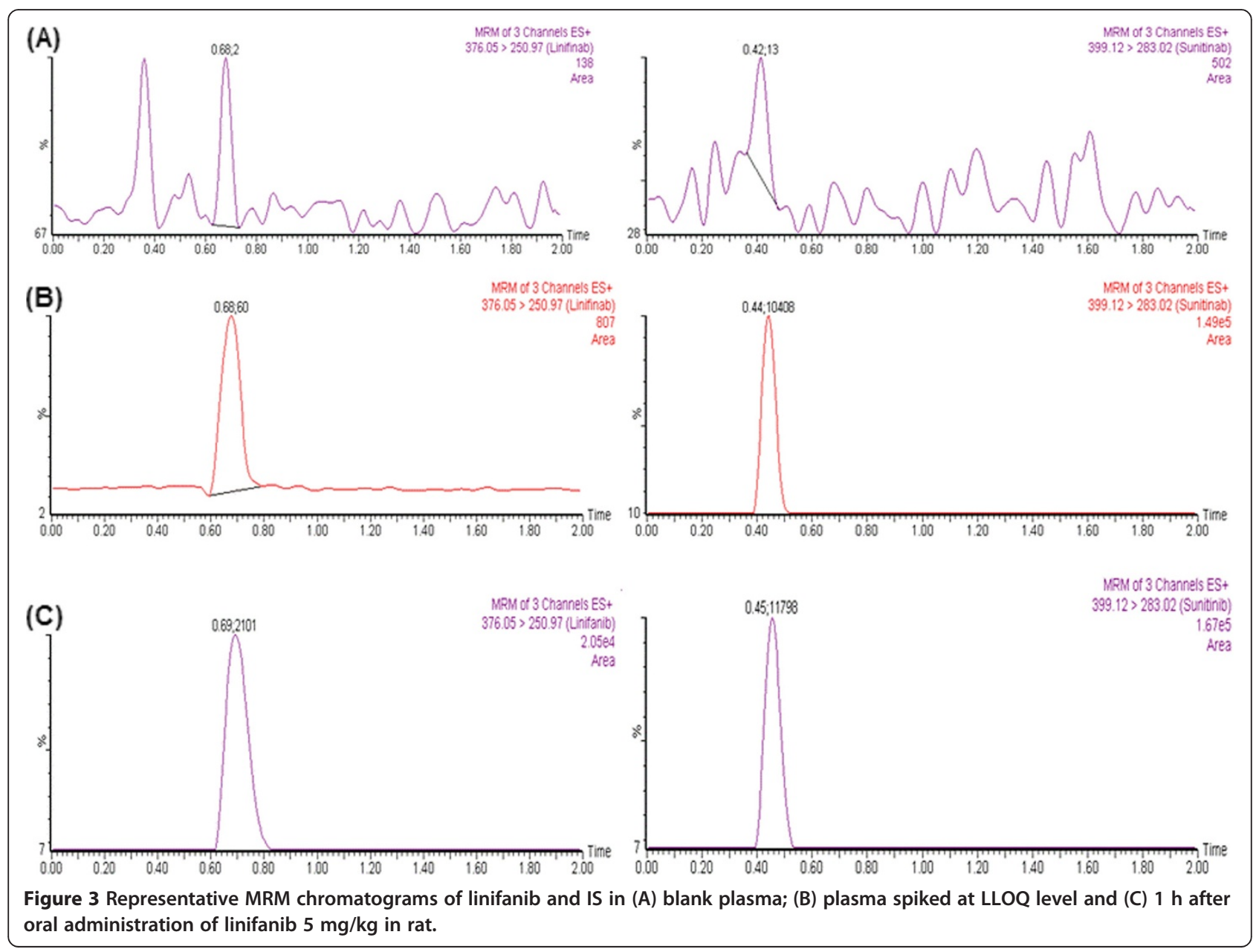


Table 1 Intraday and interday precision and accuracy of linifanib in rat plasma

\begin{tabular}{|c|c|c|c|c|}
\hline \multirow[t]{2}{*}{ Nominal concentration $(\mathrm{ng} / \mathrm{mL})$} & \multirow[t]{2}{*}{ Run } & \multicolumn{3}{|c|}{ Rat plasma } \\
\hline & & Mean \pm SD & Precision $(\% \mathrm{CV})$ & Accuracy (\%) \\
\hline \multicolumn{5}{|c|}{ Intraday variation (six replicate at each concentration) } \\
\hline \multirow[t]{3}{*}{0.45} & 1 & $0.48 \pm 0.05$ & 10.4 & 107.0 \\
\hline & 2 & $0.47 \pm 0.05$ & 10.6 & 104.4 \\
\hline & 3 & $0.49 \pm 0.05$ & 10.2 & 108.9 \\
\hline \multirow[t]{3}{*}{1.28} & 1 & $1.35 \pm 0.14$ & 10.4 & 105.3 \\
\hline & 2 & $1.38 \pm 0.14$ & 10.1 & 105.0 \\
\hline & 3 & $1.35 \pm 0.08$ & 5.9 & 105.6 \\
\hline \multirow[t]{3}{*}{42.5} & 1 & $44.5 \pm 3.28$ & 7.4 & 104.6 \\
\hline & 2 & $39.7 \pm 3.58$ & 9.0 & 93.5 \\
\hline & 3 & $40.2 \pm 1.56$ & 3.9 & 94.6 \\
\hline \multirow[t]{3}{*}{425} & 1 & $397 \pm 36.4$ & 9.2 & 93.5 \\
\hline & 2 & $387 \pm 12.2$ & 3.2 & 90.9 \\
\hline & 3 & $398 \pm 13.5$ & 3.4 & 93.9 \\
\hline \multicolumn{5}{|c|}{ Interday variation (18 replicates at each concentration) } \\
\hline 0.45 & & $0.48 \pm 0.05$ & 10.4 & 106.8 \\
\hline 1.28 & & $1.36 \pm 0.09$ & 6.6 & 106.3 \\
\hline 42.5 & & $41.48 \pm 3.53$ & 8.5 & 97.6 \\
\hline 425 & & $394 \pm 22.79$ & 5.8 & 92.8 \\
\hline
\end{tabular}

analyzing six replicates of LQC and HQC. Short-term stability was assessed after keeping the plasma samples at ambient temperature for $\sim 6 \mathrm{~h}$, the freeze-thaw stability was determined after three cycles of freeze-thaw. Post-preparative stability was determined by storing the reconstituted QC samples for $\sim 48 \mathrm{~h}$ under autosampler conditions (maintained at $10^{\circ} \mathrm{C}$ ) before being analyzed. Long-term stability was assessed after storage of the test samples at around $-80^{\circ} \mathrm{C}$ for 30 days. The working solutions and stock solutions of linifanib and the IS were also evaluated for stability at room temperature for $12 \mathrm{~h}$ and at refrigerator temperature (below $10^{\circ} \mathrm{C}$ ) for 15 days. The samples were considered stable in plasma at each concentration if the deviation from the mean calculated concentration of quality control samples were within $\pm 15 \%$.

Dilution integrity was evaluated to ensure the integrity of analyte in those samples which were beyond upper limit of the standard curve and need to be diluted. A fresh stock of linifanib was prepared and spiked in plasma to get a concentration level of 1.8 times of highest standard of the usual calibration standard, and then diluted 2 and 4 times with the same plasma. Six aliquots of both dilutions were processed along with freshly spiked calibration standards and analyzed by back calculation using regression equation obtained. The integrity of the samples were considered to be maintained if percentage nominal is within $\pm 15 \%$ of nominal values and $\% \mathrm{CVs} \leq 15 \%$ at both diluted levels.

\section{Application to pharmacokinetic interaction study in rats}

To demonstrate the utility of this method, a pilot pharmacokinetic study of linifanib was performed in six male wistar albino rats weighting from 220 to $230 \mathrm{~g}$. After an overnight fasting, all rats received linifanib $(5 \mathrm{mg} / \mathrm{kg}$, oral, dissolved in HPMC). Blood samples (approximately $0.5 \mathrm{~mL}$ ) were collected from the retro-orbital plexus into heparinized microfuge tubes at different time interval

Table 2 Recovery data of linifanib (three QC samples) and IS in rat plasma (Mean \pm SD)

\begin{tabular}{lll}
\hline & Nominal concentration $\mathbf{( n g} / \mathbf{m L})$ & Percentage recovery \\
\hline Linifanib (Analyte) & 1.28 & 82.5 \\
& 42.5 & 67.3 \\
& 425 & 65.7 \\
Sunitinib (IS) & & $71.8 \pm 9.2$ \\
\hline
\end{tabular}


Table 3 Stability and dilution integrity data of linifanib in rat plasma

\begin{tabular}{lllll}
\hline Stability & Nominal concentration $\mathbf{( n g} / \mathbf{m L})(\mathbf{n}=\mathbf{6})$ & Mean \pm SD & Precision (\% CV) & Accuracy (\%) \\
\hline Bench top (6 hrs) & 1.28 & $1.35 \pm 0.06$ & 4.4 & 105.0 \\
& 425 & $393 \pm 34.8$ & 8.9 & 101.1 \\
Freeze thaw (3 cycle) & 1.28 & $1.30 \pm 0.10$ & 7.7 & 90.7 \\
& 425 & $385 \pm 14.3$ & 3.7 & 110.6 \\
In injector (48 hrs) & 1.28 & $1.42 \pm 0.09$ & 6.3 & 107.2 \\
& 425 & $455 \pm 19.8$ & 4.4 & 98.3 \\
$\mathbf{3 0}$ days at $-\mathbf{8 0}^{\circ} \mathbf{C}$ & 1.28 & $1.26 \pm 0.10$ & 7.9 & 90.5 \\
& 425 & $384 \pm 20.2$ & 5.3 & 100.7 \\
Dilution integrity & 225 & & & 98.9 \\
\hline
\end{tabular}

after linifanib administration and plasma samples were harvested by centrifuging the blood at $4500 \mathrm{rpm}$ for $8 \mathrm{~min}$ and stored frozen at $-80 \pm 10^{\circ} \mathrm{C}$ until analysis. The pharmacokinetic parameters: $\mathrm{C}_{\max }, \mathrm{T}_{\max }, \mathrm{AUC}, \mathrm{t}_{1 / 2}$ and $\mathrm{K}_{\mathrm{el}}$ were calculated using WinNonlin software.

\section{Result and discussion \\ Method development \\ Optimization of mass spectroscopy condition}

Expecting high selectivity and sensitivity of the MS/MS detection, operation parameters were carefully optimized before detection by MRM mode. Initially, linifanib and IS response were evaluated by directly infusing into the mass spectrometer for tuning in both positive and negative ESI mode. It was observed that the signal intensity of positive ion $\left(\mathrm{ESI}^{+}\right)$was much higher than that of negative ion for both analyte and IS. Parameters, such as capillary and cone voltage, desolvation temperature, ESI source temperature and flow rate of desolvation gas and cone gas were optimized to obtain the optimum intensity of protonated molecular ions $(\mathrm{M}+\mathrm{H})^{+}$for linifanib and IS. Linifanib produced the maximum intensity of daughter ion signals when cone voltage and collision energy was set at $46 \mathrm{~V}$ and $30 \mathrm{eV}$ respectively, whereas for IS the optimized cone voltage and collision energy was $36 \mathrm{~V}$ and $22 \mathrm{eV}$ respectively. The MS spectra (parent ions) and MS/MS spectra (product ions) of linifanib and IS are shown in Figure 2.

\section{Optimization of chromatographic conditions}

Several other RTKs (gefitanib, crazotinib and sunitinib) were tested initially for the selection of appropriate IS. Finally sunitinib was chosen due to its similarity in chemical structure and polarity with linifanib and also high recovery. Binary mixture of volatile buffers (e.g. ammonium acetate and formate) and polar organic solvent like acetonitrile and methanol comprises the majority of mobile phase utilized for liquid chromatography tandem mass spectroscopy and are striking for use due to their miscibility, low viscosity, ability to produce good chromatographic peak shape and compatibility with MS/MS detection. So the feasibility of different compositions of acetonitrile or methanol with ammonium acetate were tried for separation of the analyte and IS with altered flow-rates (in the range of $0.2-0.4 \mathrm{~mL} / \mathrm{min}$ ) on $\mathrm{BEH}^{\mathrm{mm}}$ C18 column $(50 \times 2.1 \mathrm{~mm}$, i.d. $1.7 \mu \mathrm{m})$. The best peak resolution along with high sensitivity was achieved with an isocratic elution by a mobile phase comprising of acetonitrile: $10 \mathrm{mM}$ ammonium acetate $(60: 40)$ at a flow-rate of $0.3 \mathrm{~mL} / \mathrm{min}$.

\section{Optimization of sample processing}

Clean samples are essential to minimize ion suppression and matrix effect in bioanalytical method. For its simplicity, protein precipitation was investigated as the first option for sample preparation. Phospholipids present in plasma are considered as one of the most significant matrixes interferences encounter in protein preparation methodologies [19]. Due to ease and compatibility with mobile phase, protein precipitation using acetonitrile and

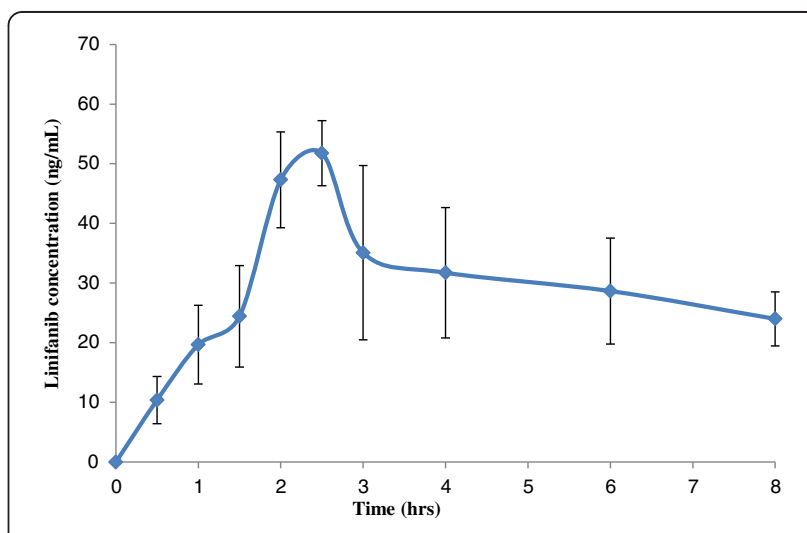

Figure 4 Mean $\pm S D$ plasma concentration- time curves of linifanib after a single oral dose of $5 \mathrm{mg} / \mathrm{kg}$ in rats. 
methanol (with or without acetic acid/formic acid) were tried. Acidification of plasma by formic acid followed by protein precipitation by acetonitrile produced maximum recovery and therefore used for sample preparation.

\section{Method validation Selectivity}

No peaks ( $\geq 20 \%$ in comparison to the spiked LLOQ and $\geq 5 \%$ in comparison to IS) were detected in blank plasma (obtained from different rats) at the corresponding retention time of linifanib and IS. This indicates that the method looks to be selective enough for quantification of linifanib. Representative MRM chromatograms of linifanib and IS for blank plasma (showing no significant interference at the retention time of the analyte and IS), plasma spiked at LLOQ level and at $1 \mathrm{~h}$ after administration of linifanib are shown in Figure 3.

\section{Linearity and lower limit of quantification}

The linearity was calculated by weighted least squares regression analysis $\left(1 / \mathrm{X}^{2}\right)$ of analyte/IS peak area ratios versus analyte concentration. The method was found to be linear in the range of $0.40-500 \mathrm{ng} / \mathrm{mL}$ for linifanib in rat plasma. The correlation coefficients $\left(\mathrm{r}^{2}\right)$ were found to be consistently $\geq 0.996$ during the course of validation. The lowest point on the standard curve was accepted as LLOQ $(0.40 \mathrm{ng} / \mathrm{mL})$ for this assay.

\section{Precision and accuracy}

Accuracy and precision were calculated based on three batches of the four QC samples. The intra- and inter-day precision values were $\leq 10.6$ and $\leq 10.4$ respectively. Likewise the intra- and inter-day accuracies were in the range of 90.9-108.9 and 92.8 - 106.8\%, respectively (Table 1). The precision values should not exceed $\pm 15 \%$ and accuracy was required to be within $\pm 15 \%$ ( $20 \%$ for LOQ QC).

\section{Recovery and matrix effects}

The extraction efficiency of the method was determined by the percentage recoveries of linifanib obtained from plasma at three different QC concentration levels (1.28, 42.5 and $425 \mathrm{ng} / \mathrm{mL})$ and IS $(100 \mathrm{ng} / \mathrm{mL})$. The mean percentage recovery was $71.8 \pm 9.2 \%$ for linifanib and $75.1 \%$ for IS (Table 2). These results indicate that the recovery of linifanib using protein precipitation method by acetonitrile was satisfactory, consistent and concentration independent. The matrix effects were examined to assess the possibility of the ionization suppression or enhancement. The data for matrix effects were in the range of $\pm 15 \%$, indicating no significant matrix effects.

\section{Stability and dilution integrity}

The stability results of freeze-thaw, post preparative, short-term and long-term are summarized in Table 3.
Results indicate that linifanib spiked into rat plasma was stable during three freeze-thaw cycle, at least $6.0 \mathrm{~h}$ at room temperature, $48 \mathrm{~h}$ in autosampler and up to 30 days at around $-80^{\circ} \mathrm{C}$. The stock solutions and working standard of linifanib and IS were also stable for 15 days at refrigerator temperature (below $10^{\circ} \mathrm{C}$ ) and for $12 \mathrm{~h}$ at room temperature. In dilution integrity study, the percentage accuracy of two and four times diluted samples were 98.9 and $100.7 \%$ of the nominal concentration for linifanib. These results concluded that the dilution of the concentrated plasma sample up to four times maintains legibility and integrity of linifanib concentration.

\section{Pharmacokinetic study in rats}

The developed method was applied to analyse the linifanib concentration in the rats plasma After oral administration of linifanib $(5 \mathrm{mg} / \mathrm{kg})$, mean peak plasma concentration of $55.09 \mathrm{ng} / \mathrm{mL}$ were achieved after 2.5 hrs. The mean AUC $_{0-8 \mathrm{~h}}$ was $232.05 \mathrm{ng} . \mathrm{hr} / \mathrm{mL}$ and average $\mathrm{t}_{1 / 2}$ and $\mathrm{K}_{\mathrm{el}}$ of $6.67 \mathrm{~h}$ and $0.10 \mathrm{hr}^{-1}$ respectively. The mean plasma concentration versus time profile of linifanib in rats is shown in Figure 4.

\section{Conclusion}

A selective and sensitive UHPLC-MS/MS method was developed and validated for the determination of linifanib (ABT-869) in rat plasma for the first time. Compared to previous reported method in human plasma, this method is more sensitive, rapid and simple in terms of chromatographic separation. The developed method was applied to determine the plasma concentrations of linifanib in rats in a pilot pharmacokinetic study. The simplicity and broad calibration range of this assay can be applicable to further characterize linifanib in drug development.

\section{Abbreviations \\ UHPLC-MS/MS: Ultra high performance liquid chromatography tandem mass spectroscopy; TKI: Tyrosine kinase inhibitor; VEGFR: Vascular endothelial growth factor recepror; PDGFR: Platelet derived growth factor receptor; LLOQ: Lower limit of quantification; LLOQ QC: Lower limit of quantification for quality control; LQC: Low quality control; MQC: Middle quality control; HQC: High quality control; ESI: Electrospray ionization; MRM: Multiple reaction monitoring; HPMC: Hydroxyl propyl methyl cellulose; $C_{\text {max }}$ : Maximum plasma concentration; $T_{\max }$ : Time to $C_{\max }$ i $A \cup C$ : Area under curve; $t_{1 / 2}$ : Half-life; Kel: Elimination rate constant.}

\section{Competing interests}

The authors declare that they have no conflict of interests.

\section{Authors' contribution}

$\mathrm{Ml}$ conducted the development and validation of the method, manuscript writing; EE: Performed the pharmacokinetic study and rat samples analysis. NYK: Designed the study and arranged the reference standard; TAW: Assisted in method validation and manuscript writing. All authors have read and approved the final version of the manuscript.

\section{Acknowledgments}

The authors extend their appreciation to the Deanship of Scientific Research at King Saud University for funding the work through the research group project No. RGP-VPP-203. 
Received: 28 November 2013 Accepted: 12 February 2014

Published: 17 February 2014

\section{References}

1. Bergers G, Song S, Meyer-Morse N, Bergsland E, Hanahan D: Benefits of targeting both pericytes and endothelial cells in the tumor vasculature with kinase inhibitors. J Clin Invest 2003, 111(9):1287-1295.

2. Erber R, Thurnher A, Katsen AD, Groth G, Kerger H, Hammes HP, Menger MD, Ullrich A, Vajkoczy P: Combined inhibition of VEGF and PDGF signaling enforces tumor vessel regression by interfering with pericyte-mediated endothelial cell survival mechanisms. FASEB J 2004, 18(2):338-340.

3. Dai Y, Hartandi K, Ji Z, Ahmed AA, Albert DH, Bauch JL, Bouska JJ, Bousquet PF, Cunha GA, Glaser KB, et al: Discovery of N-(4-(3-amino-1H-indazol-4-yl) phenyl)-N'-(2-fluoro-5-methylphenyl)urea (ABT-869), a 3-aminoindazolebased orally active multitargeted receptor tyrosine kinase inhibitor. J Med Chem 2007, 50(7):1584-1597.

4. Albert DH, Tapang P, Magoc TJ, Pease LJ, Reuter DR, Wei RQ, Li J, Guo J, Bousquet PF, Ghoreishi-Haack NS, et al: Preclinical activity of ABT-869, a multitargeted receptor tyrosine kinase inhibitor. Mol Cancer Ther 2006, 5(4):995-1006.

5. Guo J, Marcotte PA, McCall JO, Dai Y, Pease LJ, Michaelides MR, Davidsen SK, Glaser KB: Inhibition of phosphorylation of the colony-stimulating factor-1 receptor (c-Fms) tyrosine kinase in transfected cells by ABT-869 and other tyrosine kinase inhibitors. Mol Cancer Ther 2006, 5(4):1007-1013.

6. Tan EH, Goss GD, Salgia R, Besse B, Gandara DR, Hanna NH, Yang JC, Thertulien R, Wertheim M, Mazieres J, et al: Phase 2 trial of Linifanib (ABT-869) in patients with advanced non-small cell lung cancer. J Thorac Oncol 2011, 6(8):1418-1425.

7. Toh HC, Chen PJ, Carr BI, Knox JJ, Gill S, Ansell P, McKeegan EM, Dowell B, Pedersen $M$, Qin Q, et al: Phase 2 trial of linifanib (ABT-869) in patients with unresectable or metastatic hepatocellular carcinoma. Cancer 2013, 119(2):380-387.

8. Tannir NM, Wong YN, Kollmannsberger CK, Ernstoff MS, Perry DJ, Appleman LJ, Posadas EM, Cho D, Choueiri TK, Coates A, et al: Phase 2 trial of linifanib (ABT-869) in patients with advanced renal cell cancer after sunitinib failure. Eur J Cancer 2011, 47(18):2706-2714.

9. Chiu YL, Carlson DM, Pradhan RS, Ricker JL: Exposure-response (safety) analysis to identify linifanib dose for a phase III study in patients with hepatocellular carcinoma. Clin Ther 2013, 35(11):1770-1777.

10. Asahina H, Tamura $Y$, Nokihara H, Yamamoto N, Seki $Y$, Shibata T, Goto $Y$, Tanioka M, Yamada Y, Coates A, et al: An open-label, phase 1 study evaluating safety, tolerability, and pharmacokinetics of linifanib (ABT-869) in Japanese patients with solid tumors. Cancer Chemother Pharmacol 2012, 69(6):1477-1486.

11. Wong $\mathrm{Cl}$, Koh TS, Soo R, Hartono S, Thng CH, McKeegan E, Yong WP, Chen CS, Lee SC, Wong J, et al: Phase I and biomarker study of ABT-869, a multiple receptor tyrosine kinase inhibitor, in patients with refractory solid malignancies. J Clin Oncol 2009, 27(28):4718-4726.

12. Rodila RC, Kim JC, Ji QC, El-Shourbagy TA: A high-throughput, fully automated liquid/liquid extraction liquid chromatography/mass spectrometry method for the quantitation of a new investigational drug ABT-869 and its metabolite A-849529 in human plasma samples. Rapid Commun Mass Spectrom 2006, 20(20):3067-3075.

13. Wu H, Zhang J, Norem K, El-Shourbagy TA: Simultaneous determination of a hydrophobic drug candidate and its metabolite in human plasma with salting-out assisted liquid/liquid extraction using a mass spectrometry friendly salt. J Pharm Biomed Anal 2008, 48(4):1243-1248.

14. Kumar A, Saini G, Nair A, Sharma R: UPLC: a preeminent technique in pharmaceutical analysis. Acta Pol Pharm 2012, 69(3):371-380.

15. Li F, Maguigad J, Pelzer M, Jiang X, Ji QC: A novel 'peak parking' strategy for ultra-performance liquid chromatography/tandem mass spectrometric detection for enhanced performance of bioanalytical assays. Rapid Commun Mass Spectrom 2008, 22(4):486-494.

16. Novakova L, Matysova L, Solich P: Advantages of application of UPLC in pharmaceutical analysis. Talanta 2006, 68(3):908-918.
17. US Food and Drug Administration, Center for Drug Evaluation and Research (CDER): Guidance for industry on bioanalytical method validation. Rockville, MD: Department of Health and Human Services; 2001 [http://www.fda.gov/downloads/Drugs/Guidances/ucm070107.pdf]

18. European Medicines Agency: Guideline on bioanalytical method validation, 2011. [http://www.ema.europa.eu/docs/en_GB/document_library/Scientific_ guideline/2011/08/WC500109686.pdf]

19. Phillips GB, Dodge JT: Composition of phospholipids and of phospholipid fatty acids of human plasma. J Lipid Res 1967, 8(6):676-681.

doi:10.1186/1752-153X-8-13

Cite this article as: lqbal et al: Simple, sensitive and rapid determination of linifanib (ABT-869), a novel tyrosine kinase inhibitor in rat plasma by UHPLC-MS/MS. Chemistry Central Journal 2014 8:13.

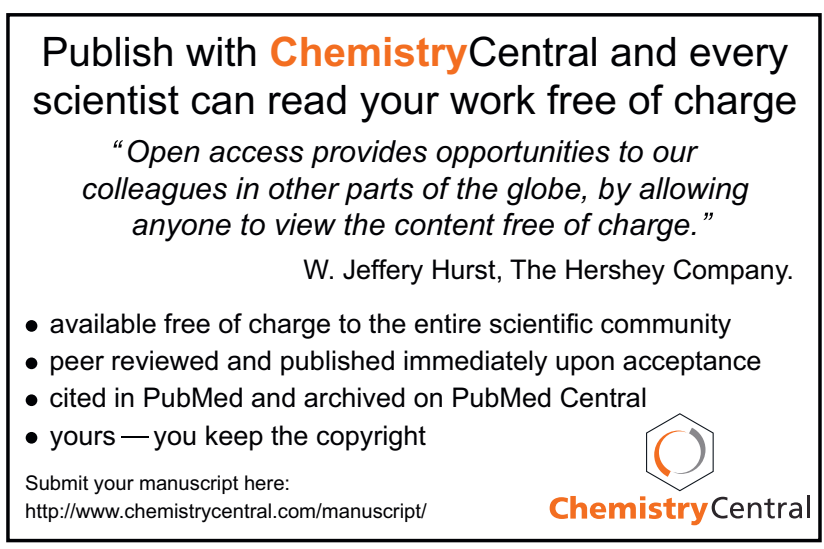

